\title{
Very Low Density Lipoprotein Metabolism in Non-Ketotic Diabetes Mellitus: Effect of Dietary Restriction
}

\author{
H. Ginsberg and S. M. Grundy \\ Department of Medicine, Division of Metabolic Diseases, University of California at San Diego School of Medicine, La Jolla, California, USA
}

\begin{abstract}
Summary. We have measured the turnover of very low density lipoprotein (VLDL) triglyceride as well as plasma glucose, insulin and non-esterified fatty acid levels in nine mildly obese non-ketotic, insulinopenic diabetic subjects before and during an energy restricted diet. During the baseline period, subjects were hypertriglyceridaemic, hyperglycaemic and insulinopenic. During dietary restriction (mean weight loss: $2.3 \pm 0.4 \mathrm{~kg}$ ) plasma triglyceride fell from $8.4 \pm 3.0$ to $3.4 \pm 0.89 \mathrm{mmol} / 1$ (mean $\pm \mathrm{SEM} ; p<0.05$ ), and plasma glucose fell from 13.9 \pm 1.7 to $9.8 \pm 1.4 \mathrm{mmol} / 1(p<0.01)$. Neither fasting plasma insulin nor the insulin response to an oral glucose load changed. Plasma non-esterified fatty acid concentrations remained constant as well. During the baseline period, the transport rate of VLDL-triglyceride in the diabetic subjects was more than twice that in an age-weighted matched control
\end{abstract}

group ( $27.4 \pm 2.9$ versus $12.1 \pm 0.8 \mathrm{mg} / \mathrm{kg}$ ideal body weight per $\mathrm{h}$ ). The fractional catabolic rates were similar in the two groups $(0.20 \pm 0.05$ versus $0.21 \pm 0.02 / \mathrm{h})$. During energy restriction of the diabetic subjects, the VLDL-triglyceride transport rate fell to $17.4 \pm 2.9 \mathrm{mg} / \mathrm{kg}$ ideal body weight per $\mathrm{h}$ ( $p<0.05$ versus baseline) while the fractional catabolic rate remained constant at $0.21 \pm 0.06 / \mathrm{h}$ (NS versus baseline). These data indicate that the major abnormality in triglyceride metabolism in these non-ketotic, insulinopenic diabetic patients was over-production of VLDL-triglyceride.

Key words: VLDL triglyceride turnover, Type 2 diabetes, effect of energy restriction, plasma lipoproteins, plasma triglyceride, plasma cholesterol.
An increased level of very low density lipoprotein (VLDL)-triglyceride is the most common lipid abnormality associated with diabetes mellitus [1-3]. The aetiology of the hypertriglycerdaemia of diabetes, although well studied, is still debated. Animal models of diabetes, studied by either in vivo [4-6] or in vitro methods [7-9] have generally led investigators to conclude that chronic, severe insulin deficiency is associated with decreased VLDL-triglyceride synthesis and secretion, and that hypertriglyceridaemia in these animals results from a defect in plasma VLDL-triglyceride removal. Studies in human hypertriglyceridaemic diabetic patients, on the other hand, have produced results supporting both defective removal from [10-12] and increased secretion of VLDL-triglyceride into plasma [13-15] as the major aetiological abnormalities in these patients. In previous studies using animal models, the duration of insulin deprivation appeared to be a significant factor in the regulation of triglyceride production $[5,16]$, while in human studies, comparison of diabetic patients with widely differing insulin secretory capacities has contributed to the heterogeneous results [12-15].
The present study was carried out to examine the rôle of overproduction and reduced catabolism in a group of well defined, non-ketotic, insulin-deficient diabetic patients. Turnover rates of VLDL-triglyceride were estimated during periods of weight maintenance and dietary restriction; the transport of triglyceride in VLDL was estimated by multi-compartmental analysis of specific activity curves of VLDL-triglyceride following injection of ${ }^{3} \mathrm{H}$-glycerol.

\section{Subjects and Methods}

All studics werc performed on inpatients in the Special Diagnostic and Treatment Unit of the V.A.Medical Center or in the General Clinical Research Center at the University Hospital, San Diego, California. Clinical characteristics of the patients upon admission are presented in Table 1. All patients had a history of ketosis-resistant diabetes mellitus for several years and had been treated with either insulin or oral hypoglycaemic agents at some time previously. However, no patient had received insulin during the previous 6 months, and oral hypoglycaemic agents were discontinued at least 4 weeks before the study. Similarly, any hypolipidaemic agents were discontinued at least 4 weeks before the studies began. None of the patients had other 
Table 1. Clinical characteristics of subject studied

\begin{tabular}{|c|c|c|c|c|c|c|}
\hline \multirow[t]{2}{*}{ Patient } & \multirow[t]{2}{*}{ Sex } & \multirow{2}{*}{$\begin{array}{l}\text { Age } \\
\text { (years) }\end{array}$} & \multirow{2}{*}{$\begin{array}{l}\text { Percentage } \\
\text { ideal body } \\
\text { weight }^{\mathrm{a}}\end{array}$} & \multicolumn{3}{|c|}{ Plasma (mmol/1) } \\
\hline & & & & Glucose $^{a}$ & $\begin{array}{l}\text { Trigly- } \\
\text { ceride }^{b}\end{array}$ & $\begin{array}{l}\text { Chole- } \\
\text { sterol }^{\text {b }}\end{array}$ \\
\hline 1 & M & 52 & 1.19 & 16.6 & 3.0 & 7.1 \\
\hline 2 & $\mathrm{~F}$ & 49 & 1.10 & 21.7 & 20.7 & 11.5 \\
\hline 3 & $\mathrm{~F}$ & 50 & 1.16 & 17.7 & 4.2 & 6.9 \\
\hline 4 & M & 45 & 1.23 & 14.9 & 24.7 & 17.6 \\
\hline 5 & $\mathrm{M}$ & 49 & 1.22 & 13.8 & 16.0 & 9.5 \\
\hline 6 & M & 65 & 1.19 & 7.1 & 5.3 & 6.0 \\
\hline 7 & M & 56 & 1.20 & 15.3 & 5.6 & 7.2 \\
\hline 8 & $\mathbf{M}$ & 63 & 1.15 & 13.4 & 3.6 & 5.6 \\
\hline 9 & M & 56 & 1.10 & 9.7 & 4.0 & 8.3 \\
\hline
\end{tabular}

a Based on Metropolitan Life Insurance tables

b Fasting plasma concentration on admission to the metabolic ward

Table 2. Effects of energy-restricted diet on weight and plasma lipids

\begin{tabular}{|c|c|c|c|c|c|}
\hline \multirow[t]{2}{*}{ Patient } & \multirow{2}{*}{$\begin{array}{l}\text { Weight } \\
\text { change } \\
(\mathrm{kg})\end{array}$} & \multicolumn{2}{|c|}{$\begin{array}{l}\text { Plasma triglycerides } \\
(\mathrm{mmol} / \mathrm{l})\end{array}$} & \multicolumn{2}{|c|}{$\begin{array}{l}\text { Plasma cholesterol } \\
\mathrm{mmol} / 1\end{array}$} \\
\hline & & Baseline & $\begin{array}{l}\text { Energy } \\
\text { restriction }\end{array}$ & Baseline & $\begin{array}{l}\text { Energy } \\
\text { restriction }\end{array}$ \\
\hline 1 & 1.2 & 1.8 & 1.6 & 6.8 & 6.5 \\
\hline 2 & 1.5 & 30.3 & 8.4 & 13.4 & 7.1 \\
\hline 3 & 3.0 & 4.1 & 2.2 & 6.2 & 6.5 \\
\hline 4 & 2.4 & 14.7 & 7.5 & 8.7 & 8.2 \\
\hline 5 & 4.3 & 5.9 & 2.4 & 5.8 & 3.3 \\
\hline 6 & 3.5 & 4.1 & 1.3 & 6.0 & 6.1 \\
\hline 7 & 1.8 & 5.3 & 2.2 & 6.6 & 4.9 \\
\hline 8 & 1.5 & 3.7 & 1.4 & 4.9 & 4.4 \\
\hline 9 & 1.7 & 5.6 & 3.2 & 8.9 & 8.4 \\
\hline \multicolumn{6}{|l|}{ Mean \pm} \\
\hline SEM & $2.3 \pm 0.4$ & $\begin{aligned} 8.4 & \pm 3.0 \\
p & <0.05\end{aligned}$ & $3.4 \pm 0.89$ & $\begin{array}{c}7.5 \pm 0.86 \\
\text { NS }\end{array}$ & $6.2 \pm 0.57$ \\
\hline
\end{tabular}

All patients had a decrease in weight; NS = not significant

diseases that might affect carbohydrate or lipid metabolism (i.e., other endocrinopathy, renal failure or liver disease). Any antihypertensive agents or beta-blocking drugs in use were continued throughout all phases of the study.

After admission, patients were started on an isocaloric (30-35 $\mathrm{kcal} / \mathrm{kg}$ ) liquid formula diet containing $15 \%$ protein, $45 \%$ carbohydrate, and $40 \%$ fat in the form of lard. The ratio of polyunsaturated to saturated fat (as percentage of total calories) was 0.4. Cholesterol intake ranged from 150 to $200 \mathrm{mg}$ /day. This diet continued for 5-7 days while fasting blood was obtained daily for measurement of plasma glucose and lipid levels. On the last baseline day, each subject received a $75 \mathrm{~g}$ oral glucose load with blood sampling at fasting and 30 , $60,90,120$ and $180 \mathrm{~min}$. These samples were used to measure plasma glucose, insulin and non-esterified free fatty acids (NEFA). Measurement of VLDL-triglyceride turnover was then carried out (see below).

Completion of this study marked the end of the baseline period and patients were then started on a $600 \mathrm{kcal}$ liquid formula diet with the same proportions of carbohydrate, fat and protein as those consumed during the baseline period. This second period, carried out with all subjects still in hospital, lasted 7-10 days with the duration determined in part by response of plasma glucose and lipid levels and also by weight change. The goal was to achieve significant decreases in the plasma triglyceride level before significant weight loss had occurred. Blood samples were obtained as in the baseline period, and a second study of VLDL-triglyceride turnover was performed at the end of the period of dietary restriction.

Turnover of VLDL-triglyceride was measured according to the protocol of Grundy et al. [17]. Patients were fed every $3 \mathrm{~h}$ using a liquid formula consisting of $75 \%$ carbohydrate and $25 \%$ protein and providing a daily caloric intake equal to $60 \%$ of their baseline period diet. This diet was chosen because fasting for $48 \mathrm{~h}$ would certainly change VLDL-triglyceride secretion rates, while a fat-free $100 \%$ calorie diet (necessary to eliminate intermittent entry of dietary triglyceride into plasma) would probably stimulate VLDL production. The present regimen has been shown to maintain the plasma VLDL-triglyceride concentration at its pre-existing level for the duration of the turnover study. Analysis of the specific radioactivity data was performed by the method of Zech et al. [18]. VLDL-triglyceride secretion rate (equal to turnover at steady state) was expressed as $\mathrm{mg} / \mathrm{kg}$ ideal body weight per $h$.

Plasma triglyceride and cholesterol and VLDL-triglyceride were measured on a Technicon AAII autoanalyzer [19]. Plasma glucose was measured by glucose oxidase method on a Beckman glucose analyzer. Plasma insulin was measured by single antibody technique [20]. This assay was sensitive to $2 \mathrm{mU} / 1$ with an interassay coefficient of variation of $11 \%$. NEFA levels were determined by the method of Noma et al. [21]. Statistical analyses were performed using Student's t-test for paired and unpaired data.

\section{Results}

Table 2 depicts effects of hypocaloric feeding on body weight and plasma lipids; the latter are values obtained on the last day of each diet period. Weight loss ranged from 1.2 to $4.3 \mathrm{~kg}$ (mean $2.3 \mathrm{~kg}$ ). Baseline plasma triglyceride averaged $8.4 \pm 3.0 \mathrm{mmol} / 1$ (mean $\pm \mathrm{SEM}$ ). Triglyceride levels dropped in eight of nine patients with a final value of $3.4 \pm 0.89 \mathrm{mmol} / \mathrm{l}$. The change in total plasma cholesterol was insignificant $(7.5 \pm 0.86$ to $6.1 \pm 0.57 \mathrm{mmol} / \mathrm{l})$.

The effects of dietary restriction on plasma glucose, insulin and NEFA levels on the final day of each period are presented in Table 3. Fasting glucose fell in eight of nine patients. No pattern of change was observed in the fasting plasma insulin between the two periods, and mean values for NEFA were unchanged. However, in some patients, NEFA concentrations increased with reduced intake of calories, while in others they decreased.

Plasma glucose and insulin responses to an oral glucose load (calculated as the area under the curve above baseline), were determined in eight diabetic patients; the test was performed at the end of each period. While the glucose response decreased significantly on hypocaloric intake, mean plasma insulin responses were unchanged $\left(17.2 \pm 1.0\right.$ versus $\left.19.0 \pm 1.5 \mathrm{mU} \cdot \mathrm{min}^{-1} \cdot 1^{-1}\right)$. In addition, comparison of insulin responses of the diabetic patients with those of ten weight- and agematched non-diabetic normal subjects clearly showed that the diabetic patients were insulinopenic during both study periods.

Table 4 presents data on the metabolism and kinetics of VLDL-triglyceride in the diabetic patients and in 27 normo-triglyceridaemic subjects. All but one of the diabetic patients had elevated VLDL-triglyceride $(2.3 \mathrm{mmol} / 1)$ during the baseline period of weight main- 
Table 3. Effects of energy-restricted diet on plasma glucose insulin and non-esterified fatty acid levels (NEFA) ${ }^{\mathrm{a}}$

\begin{tabular}{|c|c|c|c|c|c|c|}
\hline Patient & \multicolumn{2}{|c|}{ Glucose (mmol/l) } & \multicolumn{2}{|c|}{ Insulin $(\mathrm{mU} / \mathrm{l})$} & \multicolumn{2}{|c|}{$\mathrm{NEFA}(\mu \mathrm{mol} / 1)$} \\
\hline 2 & 23.2 & 19.7 & 2 & 2 & 840 & 1010 \\
\hline 3 & 18.9 & 10.3 & 16 & 8 & 940 & 1160 \\
\hline 4 & 13.4 & 9.3 & 15 & 12 & ND & ND \\
\hline 7 & 15.5 & 8.3 & 9 & 11 & 470 & 330 \\
\hline 8 & 12.1 & 7.2 & 12 & 12 & 210 & 150 \\
\hline 9 & 7.9 & 7.8 & 6 & 5 & ND & ND \\
\hline \multirow[t]{2}{*}{ Mean \pm SEM } & $13.9 \pm 1.7$ & $9.8 \pm 1.4$ & $8.6 \pm 1.7$ & $7.3 \pm 1.3$ & $634 \pm 133$ & $637 \pm 140$ \\
\hline & \multicolumn{2}{|c|}{$p<0.01$} & \multicolumn{2}{|c|}{ NS } & \multicolumn{2}{|c|}{ NS } \\
\hline
\end{tabular}

a Fasting plasma values obtained at the end of the baseline period of weight-maintenance and at the end of energy restriction. $\mathrm{ND}=$ not done; NS - not significant

Table 4. Effects of energy-restricted diet on VLDL-triglyceride metabolism

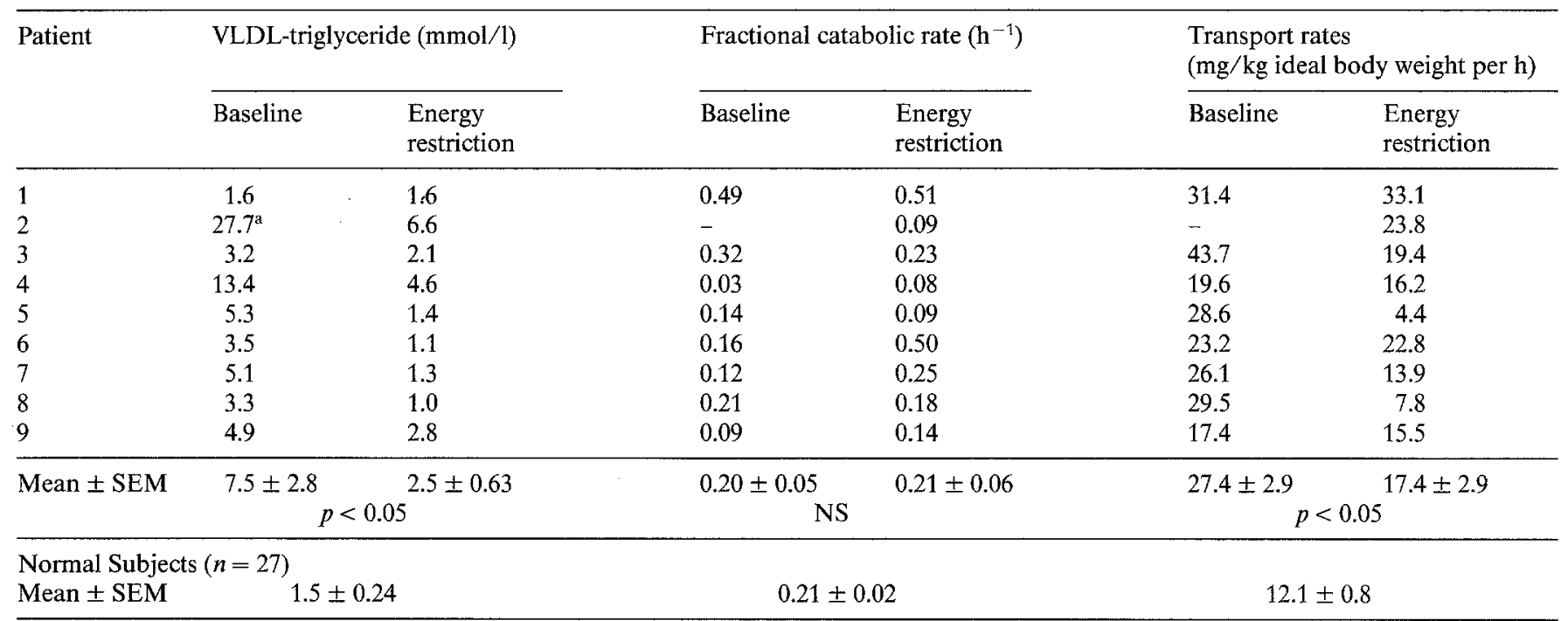

a Baseline study invalid due to large contamination of VLDL by chylomicra.

VLDL-triglyceride concentration is a single value at start of turnover study; chylomicra removed by ultracentrifugation before isolation of VLDL. NS = not significant

tenance. The mean transport rate for VLDL-triglyceride in the diabetic patients was over twice the normal means. This indicates that most of the diabetic patients had an increased synthesis of VLDL-triglyceride. For the 27 normal subjects, transport rates ranged up to $20 \mathrm{mg} / \mathrm{kg}$ ideal body weight per $\mathrm{h}$ without development of hypertriglyceridaemia (VLDL-triglyceride up to $2.3 \mathrm{mmol} / \mathrm{l}$ ). These values can therefore be called the upper limits of the normal range. In most diabetic patients, the increased concentration of VLDL-triglyceride appeared to be due mainly to enhanced synthesis rates. Indeed, one patient [1] had marked overproduction, but because of a high fractional catabolic rate, his concentration of VLDL-triglyceride remained normal.

In contrast to synthetic rates, the mean fractional catabolic rates for control subjects and diabetic patients were essentially the same. However, two patients (4 and 9) had marked hypertriglyceridaemia without distinct overproduction. They thus appeared to have a defect in clearance of VLDL-triglyceride, as revealed by their low fractional catabolic rates $(0.03$ and 0.09 per $h$, respectively). Patient 2, who had the highest baseline VLDLtriglyceride level, had a markedly reduced fractional catabolic rate $(0.9$ per $h)$ and an elevated synthetic rate during dietary restriction. Unfortunately, the baseline study in this subject was invalid because of the marked lipaemia and contamination of the VLDL by chylomicra. Three other patients (5-7) had fractional catabolic rates below the mean of the control group, but their slightly low values may have been the result of an excess synthesis with partial saturation of removal mechanisms. 
During dietary restriction, concentrations of VLDLtriglyceride were reduced in eight of nine patients. In all but three, levels fell below $2.3 \mathrm{mmol} / \mathrm{l}$. The individual responses to caloric restriction were variable. Four patients $(3,5,7$ and 8$)$ had striking reductions in transport rates of VLDL-triglyceride that contributed significantly to the reduction in triglyceride concentrations. The remaining four patients had little or no change in transport rates, and in patients 4,6 and 9, reductions in plasma VLDL-triglyceride appeared to be related mainly to an increase in clearance.

\section{Discussion}

Most of the diabetic patients in this study had hypertriglyceridaemia in the baseline state. The major cause appearing to be an overproduction of VLDL-triglyceride. This finding is in accordance with observations reported previously by other workers. For example, Nikkila and Kekki [13] and Nikkila et al. [14] estimated turnover of plasma triglyceride in untreated, non-ketotic diabetic patients using single exponential analysis of specific activity curves following injection of ${ }^{3} \mathrm{H}$-glycerol. In our view, the accuracy of this method can be questioned [18], but they nevertheless found a moderate increase in turnover rates. Greenfield et al. [15], using the same method, found similar results in non-ketosis-prone diabetic patients. The present results obtained with multicompartmental analysis of VLDL-triglyceride add strong support to the concept that the primary cause of hyertriglyceridaemia in non-ketotic diabetic patients is excessive production of VLDL-triglyceride. We have made similar observations in a group studied before and after treatment of insulin [22].

However, despite these findings, there has not been universal agreement that elevated plasma triglyceride in non-ketotic diabetic patients is due mainly to overproduction. For instance, Kissebah et al. [11] using single exponential analysis of triglyceride kinetics, claimed that defective clearance of plasma triglyceride occurs in non-obese diabetic subjects with hypertriglyceridaemia. Also, Brunzell et al. [23] determined removal rates for plasma triglyceride during constant infusion of heparin in diabetic patients with elevated plasma triglyceride levels, and their results were consistent with a catabolic defect for plasma triglyceride. Furthermore, Brunzell et al. [24] have shown that insulin-deficient diabetic patients have abnormalities in lipoprotein lipase that might also impart a defect in clearance of triglyceriderich lipoproteins.

The results of our study do not provide support for a primary clearance defect in insulin-deficient, non-ketotic diabetic subjects. The mean fractional catabolic rate for VLDL-triglyceride in our diabetic patients was not significantly lower than that in normotriglyceridaemic control subjects. Two or three diabetic patients had unusually low fractional catabolic rates which undoubted- ly contributed to their hyperglyceridaemia. However, it must be asked whether these hypertriglyceridaemic subjects were selected because of a coexistent genetic hyperlipidaemia. Brunzell et al. [25] have made the important observation that some diabetic patients also have an underlying primary hyperlipidaemia, and our few patients with a low fractional catabolic rate may have fallen into this category.

If increased synthesis of VLDL-triglyceride is the primary cause of hypertriglyceridaemia in non-ketotic diabetics, we might inquire into the contributing factors. One possible cause is obesity. Non-ketotic diabetic subjects often are obese and obesity usually stimulates synthesis of VLDL-triglyceride. However, most of our patients were $<120 \%$ of ideal weight, and thus it is unlikely that obesity played a major role. Still, similar mechanisms may hold for many diabetic patients. For example, poorly controlled diabetic subjects must ingest increased calories to maintain their weight in the face of significant glucosuria. While these excess calories in diabetic patients may be wasted, they nevertheless pass through the liver and gut and could promote production of VLDL-triglyceride. Also, the continuous hyperglycaemia of diabetics could stimulate a "carbohydrateinduced' hypertriglyceridaemia. Finally, a high level of NEFA, such as occurs in diabetes as well as in obesity, could provide the liver with excess substrate for triglyceride synthesis.

It was interesting to observe the influence of reduced intake of calories on metabolism of triglyceride in our patients. Almost all the patients had a decrease in triglyceride concentrations, as observed in non-diabetic subjects [26-28]. However, this effect was not uniformly the result of a reduction in synthesis of VLDL-triglyceride. The reasons for a failure to achieve a uniform decrease in synthesis rates are not clear, but results obtained for fasting plasma glucose and NEFA may provide a clue. Several exampes might be cited. Patient 1 had no change in VLDL-triglyceride transport, and this lack of change may have been related to the rise in NEFA levels in this patient during dietary restriction. The presence of little change in either NEFA or glucose in patient 6 might also account for the lack of change in VLDL-triglyceride transport. On the other hand, patients 5,7 and 8 each had a marked drop in both glucose and NEFA and synthetic rates of VLDL-triglyceride fell dramatically in all three. Although these comparisons are limited, they nevertheless suggest that the response in synthesis of VLDL-triglyceride can be dependent on the metabolic status of the precursors (i.e., glucose and NEFA levels).

A fall in production of VLDL-triglyceride with dietary restriction can be understood on the basis of current concepts. With reduced intake of calories, the total delivery of energy substrates to the liver during each 24-h period should be reduced. This, in turn, should decrease triglyceride synthesis. The case for an increase in clearance in some of the subjects during dietary restric- 
tion is not so easily explained. One possibility is that the increase in fractional catabolic rate was not due to enhanced clearance capacity, but instead was the result of a decreased 'saturation' of removal mechanisms by small reductions of triglyceride production. This mechanism could account for the apparent increase in clearance noted in patients 4 and 9 who may have had a concomitant primary hyperlipidaemia. The possibility that reduced intake of calories may actually enhance removal capacity must be considered, but a mechanism for such an action has not been demonstrated.

In summary, these studies indicate that the primary cause of hypertriglyceridaemia in patients with non-ketotic, insulin-deficient diabetes is an overproduction of VLDL-triglyceride. In most patients, this overproduction, when it was not coupled with a removal defect, usually caused a rise in total triglyceride to the range of 2.8 to $5.6 \mathrm{mmol} / \mathrm{l}$. A few patients, such as 2 and 4 , had a plasma triglyceride in the range of $11.3-22.6 \mathrm{mmol} / 1$. These patients probably had at least mild overproduction of VLDL-triglyceride secondary to their diabetes, but they seemingly had a concomitant clearance defect. In all likelihood, the latter abnormality was secondary to a primary hyperlipidaemia [25]. While dietary restriction seemingly corrected the 'overproduction defect' in most diabetic patients, the abnormality in clearance noted in a few patients was not adequately corrected by dietary restriction and they remained hypertriglyceriaemic.

Acknowledgements. This work was supported by National Institutes of Health grants AM-16667 and HL-14197.

\section{References}

1. Wilson DE, Schriebman PH, Day VC, Arky RA (1970) Hyperlipidemia in an adult diabetic population. J Chron Dis 23: $501-506$

2. Schonfeld G, Birge E, Miller JP, Kessler G, Santiago J (1974) Apolipoprotein B levels and altered lipoprotein composition in diabetes. Diabetes 23: 825-834

3. Kaufman RL, Assal PH, Soeldner JS, Wilmhurst EG, Lemaire JR, Gleason RE, White P (1975) Plasma lipid levels in diabetic children. Diabetes 24: 672-679

4. Basso LV, Havel RJ (1970) Hepatic metabolism of free fatty acids in normal and diabetic dogs. J Clin Invest 49: 537-547

5. Reaven EP, Reaven GM (1974) Mechanism for development of diabetic hypertriglyceridemia in streptozoticin-treated rats. $\mathrm{J}$ Clin Invest 54: 167-1178

6. Bierman EL, Amaral JA, Belknap BH (1966) Hyperlipemia and diabetes mellitus. Diabetes 15: 675-679

7. Heimberg M, Dunkerley A, Brown TO (1966) Hepatic lipid metabolism in experimental diabetes. I. Release and uptake of triglycerides by perfused livers from normal and alloxan-diabetic rats. Biochim Biophys Acta 125: 252-264

8. Woodside WF, Heimberg M (1972) Hepatic metabolism of free fatty acid in experimental diabetes. Isr J Med Sci 8: 309-316

9. McGarrey JD, Wright PH, Foster DW (1975) Hormonal control of ketogenesis. Rapid activation of hepatic ketogenic capacity in fed rats by anti-insulin serum and glucagon. J Clin Invest 55: 1202-1209
10. Lewis B, Mancini M, Mattock M, Chait A, Fraser TR (1972) Plasma triglyceride and fatty acid metabolism in diabetes mellitus. Eur $\mathrm{J}$ Clin Invest $2: 445-453$

11. Kissebah AH, Adams PW, Wynn V (1974) Interrelationship between insulin secretion and plasma free fatty acid and triglyceride transport kinetics in majority onset diabetes and the effect of phenyl ethyl biguamide. Diabetologia 10: 119-130

12. Bagdade JD, Porte D, Bierman EL (1967) Diabetic lipemia. A form of acquired fat-induced lipemia. N Eng J Med 276: 427-433

13. Nikkila EA, Kekki M (1973) Plasma triglyceride transport kinetics in diabetes mellitus. Metabolism 22: 1-22

14. Nikkila EA, Huttinen JK, Ehnholm C (1977) Postheparin lipoprotein lipase and hepatic lipase in diabetes mellitus. Diabetes 26 : $11-21$

15. Greenfield M, Kolterman O, Olefsky J, Reaven G (1980) Mechanism of hypertriglyceridaemia in diabetic patients with fasting hyperglycaemia. Diabetologia 18: 441-446

16. Balasse EO, Bier DM, Havel RJ (1972) Early effects of anti-insulin serum on hepatic metabolism of plasma free fatty acids on dogs. Diabetes 21:280-288

17. Grundy SM, Mok HYI, Zech L, Steinberg D, Berman M (1979) Transport of very low density lipoprotein triglycerides in varying degrees of obesity and hypertriglyceridemia. J Clin Invest 62: 1274-1283

18. Zech LA, Grundy SM, Steinberg D, Berman M (1979) A kinetic model for production and metabolism of very low density lipoprotein triglycerides: evidence for a slow production pathway and results for normolipidemic subjects. J Clin Invest 63: 1262-1273

19. Lipid and Lipoprotein Analysis (1974) In: Manual of laboratory operations. Lipid Research Clinic Program. Department of Health Education and Welfare Publication NIH/75-628, Government Printing Office, Washington, DC

20. Desbuquois B, Aurbach G (1971) Use of polyethylene glycol to separate free and antibody bound peptide hormones in radioimmunoassays. J Clin Endocrinol Metab 33: 732-738

21. Noma A, Okabe H, Keta M (1973) A new colorimetric micro-determination of free fatty acids in serum. Clin Chem Acta 43: $317-320$

22. Abrams JJ, Ginsberg H, Grundy SM (1981) Metabolism of cholesterol and plasma triglycerides in nonketotic diabetes mellitus. Diabetes (in press)

23. Brunzell JD, Porte D, Bierman EL (1979) Abnormal lipoprotein lipase mediated plasma triglyceride removal in untreated diabetes mellitus associated with hypertriglyceridemia. Metabolism 28: 901-907

24. Brunzell JD, Porte D, Bierman EL (1975) Reversible abnormalities in postheparin lipolytic activity during the late phase of release in diabetes mellitus. Metabolism 24: 1123-1137

25. Brunzell JD, Hazzard WR, Motulsky AG, Bierman EL (1975) Evidence for diabetes mellitus and genetic forms of hypertriglyceridemia as independent entities. Metabolism 24: 1115-1123

26. Olefsky J, Reaven GM, Farquhar JW (1974) Effects of weight reduction on obesity. J Clin Invest 53:64-76

27. Nestel PJ, Carroll KF, Havenstein N (1970) Plasma triglyceride response to carbohydrates, fats and caloric intake. Metabolism 19: $1-18$

28. Streja DA, Marliss EB, Steiner G (1977) The effects of prolonged fasting on plasma triglyceride kinetics in man. Metabolism 26: $505-516$

Received: 3 November 1981

and in revised form: 28 June 1982

Henry N. Ginsberg, M.D.

Department of Medicine

Mount Sinai School of Medicine

Gustave L. Levy Place

New York, NY 10029

USA 